\title{
Segmentasi Citra menggunakan Support Vector Machine (SVM) dan Ellipsoid Region Search Strategy (ERSS) Arimoto Entropy berdasarkan Ciri Warna dan Tekstur
}

\author{
Lukman Hakim $^{1}$, Siti Mutrofin ${ }^{2}$, Evy Kamilah Ratnasari ${ }^{3}$ \\ ${ }^{1}$ Teknik Informatika, Fakultas Teknik, Universitas Yudharta, Pasuruan \\ ${ }^{2}$ Sistem Informasi, Fakultas Teknik, Universitas Pesantren Tinggi Darul Ulum (Unipdu), Jombang \\ ${ }^{3}$ Teknik Informatika, Fakultas Teknik, Universitas Dr. Soetomo, Surabaya \\ E-mail: ${ }^{1}$ elh4keem@gmail.com, ${ }^{2}$ sitimutrofin@ft.unipdu.ac.id, ${ }^{3}$ evykaer@gmail.com
}

\begin{abstract}
Abstrak
Segmentasi citra merupakan suatu metode penting dalam pengolahan citra digital yang bertujuan membagi citra menjadi beberapa region yang homogen berdasarkan kriteria kemiripan tertentu. Salah satu syarat utama yang harus dimiliki suatu metode segmentasi citra yaitu menghasilkan citra boundary yang optimal.Untuk memenuhi syarat tersebut suatu metode segmentasi membutuhkan suatu klasifikasi piksel citra yang dapat memisahkan piksel secara linier dan non-linear. Pada penelitian ini, penulis mengusulkan metode segmentasi citra menggunakan SVM dan entropi Arimoto berbasis ERSS sehingga tahan terhadap derau dan mempunyai kompleksitas yang rendah untuk menghasilkan citra boundary yang optimal. Pertama, ekstraksi ciri warna dengan local homogeneity dan ciri tekstur dengan menggunakan Gray Level Co-occurrence Matrix (GLCM) yang menghasilkan beberapa fitur. Kedua, pelabelan dengan Arimoto berbasis ERSS yang digunakan sebagai kelas dalam klasifikasi. Ketiga, hasil ekstraksi fitur dan training kemudian diklasifikasi berdasarkan label dengan SVM yang telah di-training. Dari percobaan yang dilakukan menunjukkan hasil segmentasi kurang optimal dengan akurasi $69 \%$. Reduksi fitur perlu dilakukan untuk menghasilkan citra yang tersegmentasi dengan baik.
\end{abstract}

Kata kunci: segmentasi citra, support vector machine, ERSS Arimoto Entropy, ekstraksi ciri.

\begin{abstract}
Image segmentation is an important tool in image processing that divides an image into homogeneous regions based on certain similarity criteria, which ideally should be meaning-full for a certain purpose. Optimal boundary is one of the main criteria that an image segmentation method should has. A classification method that can partitions pixel linearly or non-linearly is needed by an image segmentation method. We propose a color image segmentation using Support Vector Machine (SVM) classification and ERSS Arimoto entropy thresholding to get optimal boundary of segmented image that noise-free and low complexity. Firstly, the pixel-level color feature and texture feature of the image, which is used as input to SVM model (classifier), are extracted via the local homogeneity and Gray Level Co-Occurrence Matrix (GLCM). Then, determine class of classifier using Arimoto based ERSS thresholding. Finally, the color image is segmented with the trained SVM model (classifier). This image segmentation result less satisfied segmented image with $69 \%$ accuracy. Feature reduction is needed to get an effective image segmentation.
\end{abstract}

Key word: image segmentation, support vector machine, ERSS Arimoto Entropy, feature extraction.

\section{Pendahuluan}

Segmentasi citra merupakan suatu metode dari pengolahan citra digital yang bertujuan untuk membagi citra menjadi beberapa region yang homogen berdasarkan kriteria kemiripan tertentu. Segmentasi citra merupakan masalah klasifikasi, yaitu bagaimana memprediksikan suatu piksel termasuk tepi atau bukan tepi. Terdapat syarat utama yang harus dimiliki oleh metode segmentasi citra, yaitu: a). Memiliki tahap preprocessing yang tepat dan efisien, b). Tahanterhadap terjadinya derau, c). Terdapat suatu classifier yang menghasilkan boundary citra yang optimal.

Pada umumnya, suatu metode segmentasi citra hanya menggunakan classifier yang linier sehingga menghasilkan boundary citra yang kurang optimal dan masih mengandung derau. Derau yang terjadi pada hasil segmentasi citra disebabkan karena adanya piksel yang missclassification. Oleh karena itu, dibutuhkan suatu metode segmentasi citra yang dapat memisahkan piksel secara non-linear 
sehingga dapat menghasilkan boundary citra yang optimal dan dapat mengurangi derau disekitar objek yang diamati.

Salah satu metode klasifikasi yang dapat digunakan dalam segmentasi citra yaitu Support Vector Machine (SVM). SVM telah berhasil diaplikasikan ke dalam masalah klasifikasi yang diperkenalkan oleh Vapnik pada 1995. Penelitian segmentasi citra yang secara otomatis mengklasifikasikan piksel (Wang, Wang, \& Bu, 2011) menggunakan SVM menunjukkan performa yang baik kemampuan SVM sebagai classifier dan meningkatkan kualitas segmentasi citra dibandingkan dengan metode yang sudah ada. Penelitian (Wang, Wang, \& Bu, 2011) menggunakan teknik klaster fuzzy c-means (FCM) untuk melatih model SVM berdasarkan ciri warna dan tekstur yang telah diekstraksi. Kelemahan dari metode tersebut adalah masih terdapat missclasification ketika diterapkan pada citra yang memiliki derau. Penelitian (Yang, Wang, Wang, \& Zhang, 2012) menggunakan SVM versi Least Square (LS-SVM) berdasarkan informasi warna dan tekstur citra sebagai classifier yang lebih efisien. Pemilihan sample sebagai training model classifier LS-SV menggunakan entropi Arimoto yang merupakan teknik thresholding karena dapat menghasilkan pemilihan data training yang cepat, stabil, dan sesuai. Segmentasi pada citra yang kompleks akan membutuhkan waktu komputasi lebih lama (Liu \& Li, 2010) dan akan mengurangi performasi. Metode yang sesuai digunakan dalam segmentasi citra yang kompleks yaitu thresholding. Penelitian (Liu \& Li, 2010) melakukan pengembangan pada Arimoto thresholding dengan Ellipsoid Region Search Strategy (ERSS) untuk mengurangi kompleksitas komputasi. Pengembangan Arimoto tersebut dengan cara memodifikasi persamaan yang digunakan dalam entropi Arimoto. ERSS menunjukkan perbandingan waktu komputasi yang signifikan lebih cepat dibandingkan dengan teknik thresholding entropi Arimoto dan Otsu. Segmentasi citra berwarna dapat menggunakan teknik klasifikasi dan thresholding sebagaimana penelitian yang dilakukan oleh (Wang, Wang, \& Bu, 2011) dan (Yang, Wang, Wang, \& Zhang, 2012). Segmentasi citra yang berdasarkan integrasi ciri warna dan tekstur lebih baik dibandingkan dengan penelitian yang berdasarkan ciri warna saja. Hal tersebut karena kedua ciri tersebut merupakan bagian alamiah dari citra berwarna dan cukup akurat dalam mendeskripsikan informasi yang terdapat dalam sebuah citra (Ilea \& Whelan, 2011).

Oleh karena itu, pada penelitian ini diusulkan metode untuk segmentasi citra berwarna menggunakan SVM sebagai classifier dan entropi Arimoto berdasarkan ERSS sebagai pelabelan kelas classifier yang menggunakan integrasi informasi ciri warna dan tekstur citra dengan tujuan segmentasi citra yang tahan terhadap derau dan mempunyai komputasi rendah sehingga menghasilkan boundary citra yang optimal.

\section{Metode Penelitian}

Segmentasi citra berwarna dengan SVM dan Arimoto ERSS menggunakan data berupa citra RGB yang diperoleh dari dataset Berkeley Segmentation Dataset (BSDS). Percobaan dilakukan dengan cara membagi piksel sebagai data menjadi data training dan testing. Secara umum implementasi SVM pada klasifikasi piksel untuk segmentasi citra dapat dilihat pada Gambar 1 yang terdiri dari ekstraksi fitur warna dengan Local Homogeneity, ekstraksi fitur tekstur dengan Gray Level Co-Occurrence Matrix (GLCM), proses pelabelan kelas model classifier dengan entropi Arimoto berbasis ERSS, proses training SVM untuk membuat model SVM dengan hyperplane terbaik yang akan dijadikan model klasifikasi piksel selanjutnya, dan klasifikasi piksel menggunakan model SVM. Keluaran dari proses ini adalah citra yang tersegmentasi.

Pada gambar tersebut dapat dilihat bahwa langkah awal yang dibutuhkan pada segmentasi citra yaitu suatu proses ekstraksi ciri sebagai tahap preprocessing. Pada penelitian ini ekstraksi ciri yang digunakan yaitu ekstraksi ciri warna dan tekstur. Ekstraksi ciri warna menggunakan metode local homogeneity (Yang, Wang, Wang, \& Zhang, 2012) untuk mendapatkan informasi warna yang samadengan piksel tetangga secara lokal sehingga dapat dikelompokkan sesuai dengan kriteria yang sama. Perhitungan local homogeneity terdiri dari dua komponen, yaitu standar deviasi yang ditunjukkan pada persamaan (1) untuk mengukur luas penyimpangan antara nilai piksel pada citra tersebut dengan nilai rata-rata pada piksel tetangganya dan discontinuity pada persamaan (3) untuk menentukan nilai tepi yang menggunakan operator Sobel. Sedangkan ekstraksi ciri tekstur menggunakan metode GLCM. Metode tersebut merupakan ekstraksi ciri untuk klasifikasi tekstur yang diusulkan oleh Haralick (Clausi \& Yue, 2004) dan merupakan suatu metode statistik yang menghitung hubungan antar pasangan piksel pada suatu citra. Ekstraksi tekstur ini menghasilkan ciri gradien, kontras, korelasi, dan energi.

12 | Register: Jurnal Ilmiah Teknologi Sistem Informasi, Januari 2016, Volume 2, Nomor 1 
$v_{i j}^{k}=\frac{1}{d^{2}} \sum_{m=i-(d-1) / 2}^{i+(d-1) / 2} \sum_{n=j-(d-1) / 2}^{j+(d+1) / 2}\left(P_{m n}^{k}-\mu_{i j}^{k}\right)^{2}$

Dimana $v_{i j}^{k}$ merupakan standar deviasi pada local window $d \times d, P_{i j}^{k}$ merupakan piksel tetangga dengan indeks piksel tetangga $m$, $n$, sedangkan $\mu_{i j}^{k}$ merupakan nilai rata-rata piksel citra dengan indeks piksel $i, j$ yang dapat dihitung persamaan (2).

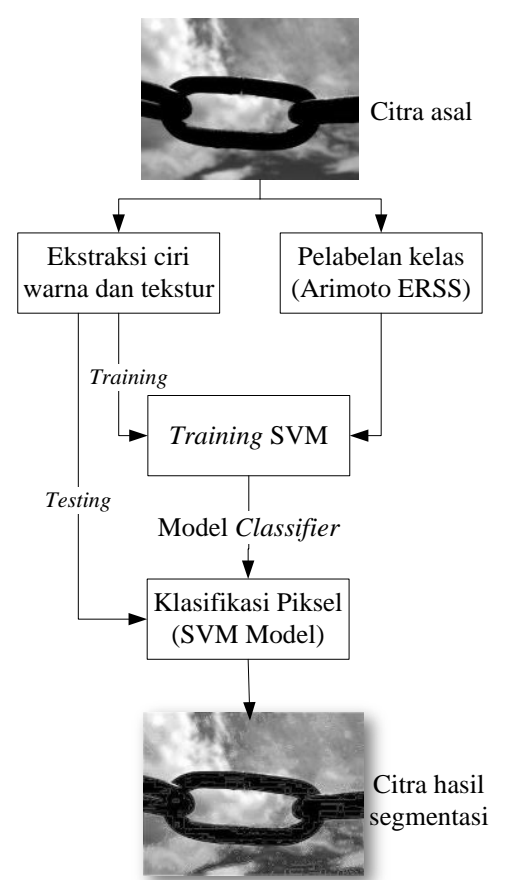

Gambar 1 Metode Segmentasi Citra menggunakan SVM dan Arimoto ERSS

$v_{i j}^{k}=\frac{1}{d^{2}} \sum_{m=i-(d-1) / 2}^{i+(d-1) / 2} \sum_{n=j-(d-1) / 2}^{j+(d+1) / 2} P_{m n}^{k}$

$G=\sqrt{G_{x}^{2}+G_{y}^{2}}$

$G_{x}$ dan $G_{y}$ merupakan dua citra di mana setiap pikselnya terdiri dari gradien horisontal dan vertikal.

Setelah dilakukan ekstraksi ciri warna dan tekstur, langkah yang bersamaan dengan ekstraksi tersebut yaitu pelabelan kelas yang akan digunakan untuk membentuk model classifier SVM dengan entropi Arimoto ERSS. Tahapan entropi Arimoto ERSS dijelaskan pada penelitian (Liu \& Li, 2010). Gambar 2 menunjukkan histogram citra yang dibagi dengan entropi Arimoto menjadi empat region.Kelas yang digunakan dalam penelitian ini yaitu objek dan latar belakang.

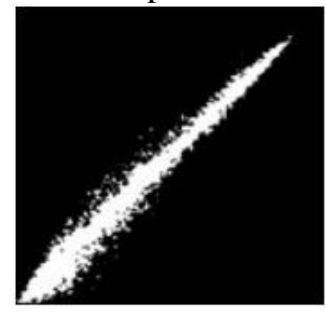

(a)

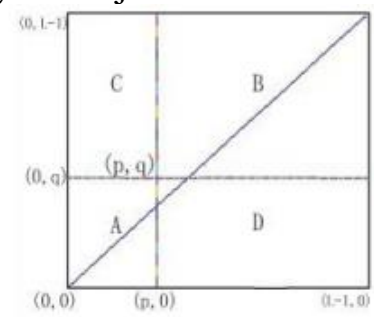

(b)

Gambar 2 Metode Segmentasi Citra menggunakan SVM dan Arimoto ERSS (Liu \& Li, 2010) 
Gambar 2(a) menunjukkan histogram dua dimensi pada suatu citra dan Gambar 2(b) membagi histogram tersebut menjadi 4 region yaitu region A merepresentasikan objek, region B merepresentasikan latar belakang, region $\mathrm{C}$ merepresentasikan tepi, dan region $\mathrm{D}$ merepresentasikan derau. Untuk mencari maksimum threshold digunakan persamaan 4.

$S^{\alpha}(p, q)=S_{0}^{\alpha}(p, q)+S_{1}^{\alpha}(p, q)-\frac{\alpha-1}{\alpha} S_{0}^{\alpha}(p, q) \times S_{1}^{\alpha}(p, q)$

$(p, q)$ merupakan titik potong dari 4 region, $S_{0}^{\alpha}(p, q)$ merupakan entropi Arimoto objek, sedangkan $S_{1}^{\alpha}(p, q)$ merupakan entropi Arimoto latar belakang. ERSS memodifikasi pada persamaan entropi Arimoto objek dan latar belakang untuk mengurangi kompleksitas dengan menggunakan thresholding Otsu satu dimensi (Liu \& Li, 2010).

SVM termasuk dalam kelas supervised learning yang memerlukan training dan testing. Tahap training berdasarkan kelas label menghasilkan model classifier SVM. Dalam melakukan klasifikasi, SVM sebelumnya melakukan pencarian hyperplane untuk mengklasifikasikan training set dengan benar. Setelah didapat model classifier SVM, kemudian digunakan untuk mengklasifikasi piksel sesuai dengan ciri masukan. Hasil dari proses tersebut yaitu citra yang tersegmentasi.

\section{Hasil Penelitian dan Pembahasan}

Penelitian ini telah melakukan serangkaian uji coba segmentasi beberapa citra data set Barkeley menggunakan metode yang diusulkan. Ukuran citra sebesar $300 \times 200$ piksel yang ditunjukkan pada Gambar 3.

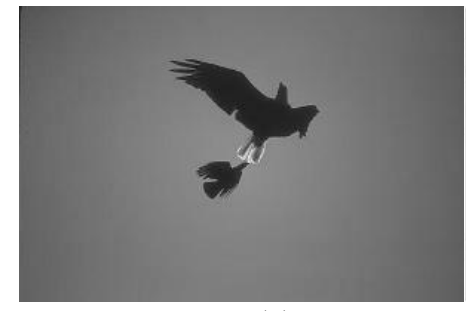

(a)

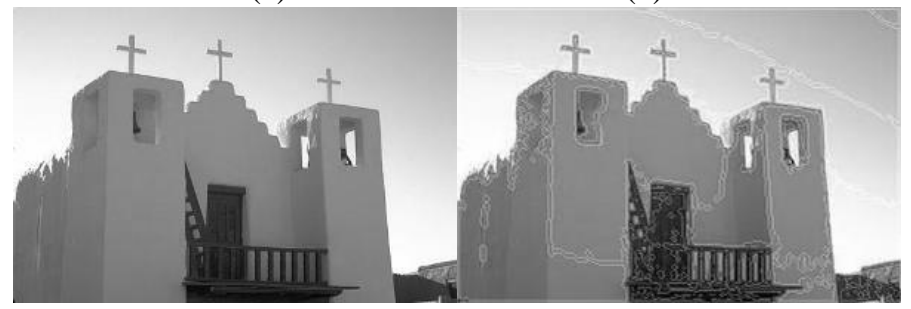

(c)

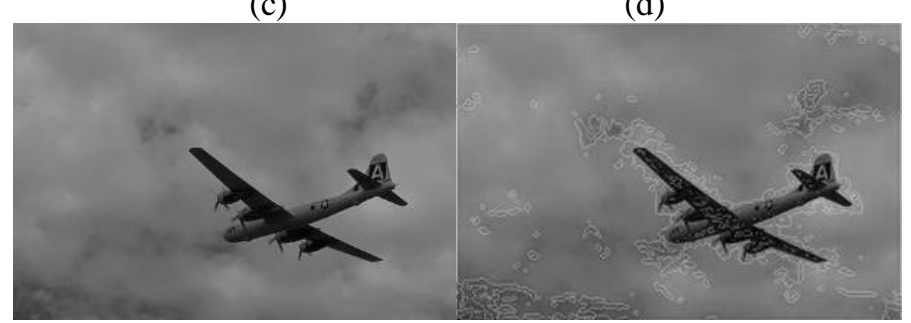

(e)

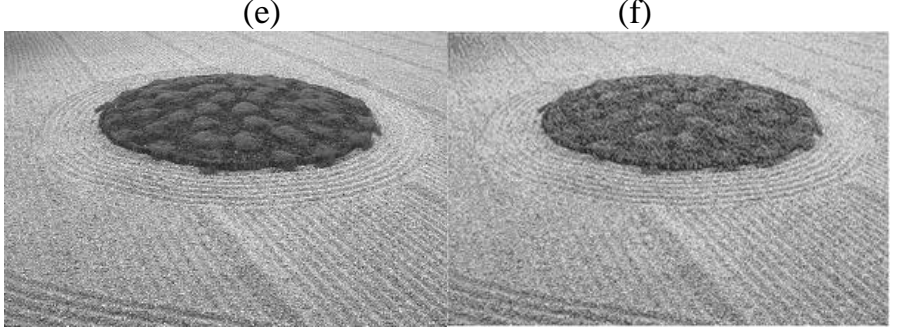

(g)

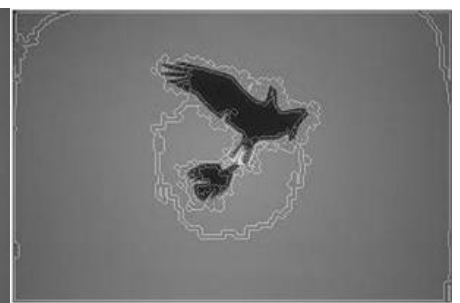

(b)

(h)

Gambar 3 (a), (c), (e), (g) Citra asli dan (b), (d), (f) dan (h) Citra tersegmentasi 
Pada Tabel 1 proses segmentasi membutuhkan waktu rata-rata 16,75 menit dan akurasi sebesar 69\%. Akurasi tertinggi diperoleh citra dengan tingkat kompleksitasnya rendah selama 15 menit, yaitu pada citra Burung dan Pesawat (Gambar 3 (a) dan (e)). Akurasi tersebut sebanding dengan ukuran file yang kecil sebesar $4 \mathrm{~KB}$ dan $6 \mathrm{~KB}$, serta sebanding dengan kompleksitas yang rendah. Sedangkan, jika dibandingkan dengan metode yang sudah ada, seperti yang diperlihatkan pada Gambar 3, metode yang diusulkan memiliki hasil yang kurang baik dibandingkan dengan metode pembanding dan lemah terhadap ukuran citra yang besar, misal pada citra dengan ukuran $400 \times 300$ piksel.

Tabel 1 Perbandingan hasil akurasi dengan ukuran piksel $300 \times 200$

\begin{tabular}{cccc}
\hline Sampel Gambar (jpg) & Ukuran File (KB) & Akurasi & Waktu (Menit) \\
\hline Burung & 4 & 0,9083 & 18 \\
Gereja & 7 & 0,5166 & 15 \\
Pesawat & 6 & 0,9036 & 19 \\
Tanaman & 21 & 0,4385 & 15 \\
\hline
\end{tabular}

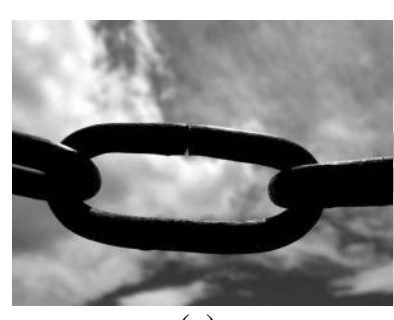

(a)

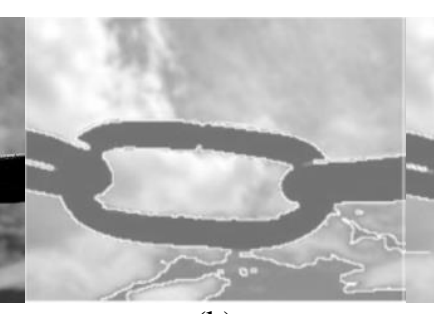

(b)

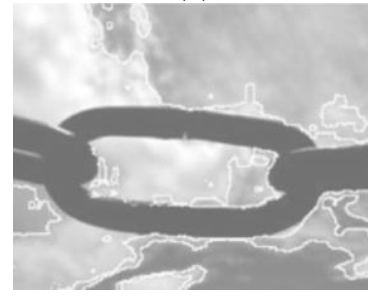

(d)

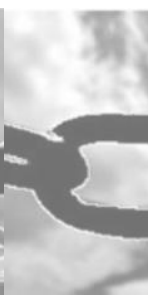

(e)

(c)

Gambar 4 Perbandingan hasil segmentasi antara metode yang sudah ada: (a) Citra asli, (b) Segmentasi citra dengan skema (Wang, Wang, \& Bu, 2011), (c) Segmentasi citra dengan mean-shift (Wang, Wang, \& Bu, 2011),

(d) Segmentasi citra dengan graph cuts (Wang, Wang, \& Bu, 2011), (e) Segmentasi citra dengan FCM-SVM

(Wang, Wang, \& Bu, 2011), dan (f) Segmentasi citra dengan metode yang penulis usulkan

\section{Kesimpulan}

Hasil segmentasi menggunakan metode yang memiliki boundary yang kurang optimal dibandingkan dengan metode-metode sebelumnya dengan akurasi $69 \%$. Penggunaan fitur yang banyak pada klasifikasi piksel mempengaruhi boundary citra dan tidak dapat dipastikan bahwa nilai akurasi yang semakin tinggi maka menghasilkan suatu boundary citra yang sempurna. Oleh karena itu diperlukan reduksi fitur menggunakan metode tertentu.

\section{Ucapan Terimakasih}

Ucapan terima kasih Penulis sampaikan kepada Bapak Agus Zainal Arifin yang telah membimbing penulis dalam pembuatan jurnal ini.

\section{Referensi}

Clausi, D. A., \& Yue, B. (2004). Comparing Cooccurrence Probabilities and Markov Random Fields for Texture Analysis of SAR Sea Ice Imagery. Geoscience and Remote Sensing, IEEE Transactions on, 42(1), 215-228.

Ilea, D. E., \& Whelan, P. F. (2011). Image Segmentation Based on The Integration of Colour-Texture. Pattern Recognition, 44(10), 2479-2501.

Liu, Y., \& Li, S. (2010). Two-Dimensional Arimoto Entropy Image Thresholding based on Ellipsoid Region Search Strategy. International Conference 2010 on Multimedia Technology (ICMT) . Ningbo. 
Wang, X. Y., Wang, T., \& Bu, J. (2011). Color Image Segmentation Using Pixel Wise Support Vector Machine Classification. Pattern Recognition, 44(4), 777-787.

Yang, H. Y., Wang, X. Y., Wang, Q. Y., \& Zhang, X. J. (2012). LS-SVM Based Image Segmentation Using Color and Texture Information. Journal of Visual Communication and Image Representation, 23(7), 1095-1112. 